\title{
Estudo da subdivisão genética da raça Mangalarga Marchador
}

[Study on genetic subdivision of the Mangalarga Marchador horse breed]

\author{
M.D. Costa $^{1}$, J.A.G. Bergmann ${ }^{2}$, A.S.C. Resende ${ }^{2}$, C.G. Fonseca ${ }^{3}$, F.J.C. Faria ${ }^{4}$ \\ ${ }^{1}$ Universidade Estadual de Montes Claros - Núcleo de Salinas-km 2, s/n \\ Fazenda Varginha-Rodovia 5 \\ 39560-000 - Salinas, MG \\ ${ }^{2}$ Escola de Veterinária da UFMG-Belo Horizonte \\ ${ }^{3}$ Instituto de Ciências Biológicas da UFMG-Belo Horizonte \\ ${ }^{4}$ Universidade Federal do Mato Grosso do Sul - Campo Grande
}

\begin{abstract}
RESUMO
Foram analisadas as informações de 233.214 animais inscritos no arquivo zootécnico da Associação Brasileira dos Criadores do Cavalo Mangalarga Marchador, descendentes de 16 ancestrais com contribuição genética mínima de até $1 \%$ para a população atual. Análises de componentes principais foram feitas com o intuito de agrupar animais geneticamente semelhantes e o de avaliar a subdivisão da raça em famílias ou grupos genéticos distintos. A média do coeficiente de parentesco entre animais da atual população e os ancestrais de maior contribuição genética variou de 4,7\%, para a égua Herdade Alteza, a 0,7\%, para o garanhão Tabatinga Fanfarra. A atual população da raça Mangalarga Marchador é constituída, em ordem de importância, por cinco grupos genéticos descendentes dos animais Herdade Alteza e Seta Caxias, Providência Itu e Tabatinga Predileto, Abaíba Marengo, Tabatinga Cossaco e Angaí Miron.
\end{abstract}

Palavras-chave: eqüino, Mangalarga Marchador, componentes principais, família, grupo genético

\begin{abstract}
Pedigree information on 233,214 animal from the studbook of the Associação Brasileira dos Criadores do Cavalo Mangalarga Marchador, related to 16 ancestors with, at least, $1 \%$ of genetic contribution to the actual population were used to describe the genetic structure of breed population. Principal component analyses were used to classify animals of the same genetic basis and to identify possible subdivision of the breed in families or genetics groups. The average relationship coefficient between each one of the ancestors and the actual breed population vary from 4.7\%, for the mare Herdade Alteza, to $.7 \%$, for the stallion Tabatinga Fanfarra. The actual breed population can be subdivided into five families, represented, in order of importance, by animals related to the ancestors Herdade Alteza and Seta Caxias, Providência Itu and Tabatinga Predileto, Abaíba Marengo, Tabatinga Cossaco and Agaí Miron.
\end{abstract}

Keywords: horse, Mangalarga Marchador, principal components, family, genetic group

\section{INTRODUÇ̃̃O}

A raça Mangalarga Marchador teve origem nas fazendas Campo Lindo, Favacho, Traituba, Narciso, Angaí e Campo Alegre, no Sul de
Minas Gerais. A partir destes seis rebanhos iniciais, considerados núcleos de criação por Bortoni (1991) e Casiuch (1997), a criação dos animais marchadores difundiu-se e, hoje, está distribuída por todas as regiões do Brasil (Costa,

Recebido para publicação em 29 de janeiro de 2004

Recebido para publicação, após modificações, em 16 de setembro de 2004

E-mail: dulcec2001@yahoo.com.br 
2002). Segundo aqueles autores, dentre os principais núcleos de criação, considerados pelos criadores como linhagens, estão as Fazendas Abaíba, Ara, Bela Cruz, FR, Herdade, Itamotinga, Passa Tempo, Porto, Tabatinga, Engenho da Serra, Juca Carneiro, Criminosos, Leme, Caxambu e Água Limpa. Casiuch (1997) dividiu as linhagens da raça Mangalarga Marchador em dois grupos, chamados de linhagens antigas e linhagens de tradição. As linhagens antigas tiveram origem nos criatórios onde se iniciou o trabalho de seleção a partir do século XIX. Os criatórios considerados nesse grupo foram Favacho, Traituba, Narciso, Campo Lindo, Tropa 53, Angaí, Engenho da Serra, Leme, Juca Carneiro, Criminosos, SilvestreGoiabal e Água Limpa. O mesmo autor considerou que algumas linhagens, como Campo Alegre, Narciso, Leme, Juca Carneiro, Criminosos, Silvestre-Goiabal e Água Limpa, se extinguiram.

Ainda, de acordo com Casiuch (1997), as linhagens de tradição foram aquelas que tiveram sua origem em animais oriundos das linhagens antigas submetidos à seleção artificial visando à fixação de caracteres como o andamento, a docilidade, a conformação e a caracterização racial, e serviram como fornecedoras de reprodutores para novas criações. Assim, foram consideradas como linhagens de tradição as que tiveram origem nas fazendas Abaíba, Providência, Sama, Cachoeirinha, Pau D'Alho, Santo Antônio, Rima, Santana, Aliança, Ara, Bela Cruz, Catuni, Garças, Caxambu, Gironda, Herdade, Itamotinga, Passa Tempo, Calciolândia, Porto, Tabatinga e $\mathrm{km} \mathrm{47,} \mathrm{do} \mathrm{Instituto} \mathrm{de}$ Zootecnia.

No século passado, a linhagem Abaíba englobou os núcleos Providência (posteriormente denominado A.J.), Sama, Cachoeirinha, Pau D'Alho, Santo Antônio, Rima e Santana (Casiuch, 1997). O autor considerou também uma linhagem denominada "oculta", em razão dos seus reprodutores terem sido utilizados tanto na raça Mangalarga Marchador como na raça Mangalarga, esta última de origem paulista. Esses garanhões, quando utilizados na raça Mangalarga Marchador, foram controlados como se fossem algum outro garanhão registrado (Casiuch, 1997).
Apesar da descrição encontrada na literatura objetivar a caracterização dos atuais animais da raça Mangalarga Marchador em diferentes linhagens, não existe, até o momento, nenhuma abordagem sobre esse assunto que utilize análises da estrutura de pedigree da raça.

O objetivo deste trabalho foi o de verificar a formação de linhagens ou subpopulações na raça Mangalarga Marchador, a partir de informações do parentesco dos animais registrados na associação da raça, utilizando-se a metodologia de componentes principais.

\section{MATERIAL E MÉTODOS}

Os dados utilizados foram oriundos dos arquivos zootécnicos da Associação Brasileira de Criadores de Cavalo Mangalarga Marchador como descritos em Costa et al. (2005). Para o cálculo dos coeficientes de parentesco, foram utilizados 233.214 animais que apresentavam algum grau de ligação genética com os ancestrais identificados como de maior contribuição genética para a população atual (Costa et al., 2005). Os coeficientes de parentesco e de endogamia foram calculados utilizando-se a rotina proposta por Meuwissen e Luo (1992), incluída no programa Pedig ${ }^{\circledR}$ (Boichard, 2002).

Para verificar a formação de grupos genéticos dentro da raça Mangalarga Marchador foram feitas análises de componentes principais. Esse tipo de análise é utilizado para descrever os fatores responsáveis por diferenças entre indivíduos, de acordo com um conjunto de respostas correlacionadas observadas numa população. $\mathrm{O}$ método consiste na transformação das variáveis originais em novas variáveis, em novos eixos, os componentes principais. Os componentes principais são ortogonais, de tal forma que as informações representadas por eles não são correlacionadas. As novas variáveis que se posicionam próximas umas das outras têm características similares e são positivamente correlacionadas, enquanto que as que se posicionam em lados opostos tendem a apresentar correlações negativas entre elas. Ainda, quanto mais distante a nova variável estiver da origem do eixo, maior será sua importância no plano considerado (Destefanis et al., 2000). A análise de componentes principais tem sido utilizada na avaliação da morfometria 
animal com diferentes objetivos, na avaliação de grupos ou raças, na discriminação entre grupos ou raças e nos estudos de morfogênese e de crescimento (Fuentes Garcia et al., 1987; Barbosa, 1991).

$\mathrm{Na}$ primeira análise utilizou-se o parentesco médio entre 16 ancestrais com contribuição genética mínima de $1 \%$ para a população atual (Costa et al., 2004) e todos os animais registrados da raça Mangalarga Marchador. A segunda análise foi feita com apenas oito animais com contribuição genética mínima de $2 \%$ para a população atual. A terceira foi feita excluindo-se o garanhão Abaíba Gim em razão de seu estreito parentesco genético com o garanhão Providência Itu.

\section{RESULTADOS E DISCUSSÃO}

Na Tab. 1 são apresentados os 16 ancestrais que tiveram contribuição genética mínima de $1 \%$ para a atual população de Mangalarga Marchador. A maior contribuição genética para a raça foi a do garanhão Providência Itu, com 5,9\% dos genes da atual população, seguido pela égua Herdade Alteza $(5,5 \%)$ e Tabatinga Predileto (4,5\%). Apesar do garanhão Malibu de Santa Terezinha ter parentesco genético diferente de zero com $66,3 \%$ dos animais incluídos no atual banco de dados da Associação, e de ter o maior número de progênies (789), sua contribuição $(1,3 \%)$ foi relativamente pequena para o pool gênico atual da raça Mangalarga Marchador. O mesmo ocorreu com o garanhão Santana Nababo, com 503 progênies identificadas e apenas $1,0 \%$ de contribuição genética atual. Isto poderia sugerir que os descendentes desses dois garanhões não foram e não estão sendo utilizados de forma intensiva como progenitores na população Mangalarga Marchador. Sabe-se que nos animais domésticos alguns indivíduos assumem importância na origem e formação da raça (Fletcher, 1945, 1946; Gazder, 1945; Rhoad e Kleberg, 1946).

Tabela 1. Ancestrais com contribuição genética mínima de até $1 \%$ para a atual população Mangalarga Marchador, ano de nascimento, sexo, número de progênies, contribuição (\%) e número de animais com alguma relação de parentesco com animais da atual população Mangalarga Marchador

\begin{tabular}{lccccc}
\hline Ancestral & $\begin{array}{c}\text { Ano de } \\
\text { nascimento }\end{array}$ & Sexo & $\begin{array}{c}\text { Número de } \\
\text { progênies }\end{array}$ & $\begin{array}{c}\text { Contribuição } \\
(\%)\end{array}$ & $\begin{array}{c}\text { Número de } \\
\text { animais }(\%)\end{array}$ \\
\hline Providência Itu & 1961 & $\mathrm{M}$ & 82 & 5,89 & $88.796(38,0)$ \\
Herdade Alteza & 1950 & $\mathrm{~F}$ & 13 & 5,45 & $102.918(44,1)$ \\
Tabatinga Predileto & & $\mathrm{M}$ & 74 & 4,46 & $66.638(28,6)$ \\
Abaíba Marengo & 1964 & $\mathrm{M}$ & 208 & 3,49 & $64.870(27,8)$ \\
Seta Caxias & & $\mathrm{M}$ & 5 & 2,85 & $86.825(37,2)$ \\
Tabatinga Cossaco & 1966 & $\mathrm{M}$ & 60 & 2,74 & $30.791(13,2)$ \\
Angaí Miron & & $\mathrm{M}$ & 203 & 2,18 & $29.085(12,5)$ \\
Abaíba Gim & 1979 & $\mathrm{M}$ & 372 & 1,70 & $120.173(51,5)$ \\
Abaíba Três Pontas & 1952 & $\mathrm{~F}$ & 10 & 1,40 & $28.079(12,0)$ \\
Providência Prenda & & $\mathrm{F}$ & 7 & 1,34 & $25.766(11,0)$ \\
Malibu de Santa Terezinha & 1982 & $\mathrm{M}$ & 789 & 1,27 & $154.518(66,3)$ \\
Tabatinga Fanfarra & & $\mathrm{F}$ & 18 & 1,19 & $18.252(7,8)$ \\
Herdade Ouro Preto & & $\mathrm{M}$ & 12 & 1,10 & $33.102(7,8)$ \\
Abaíba Jurema & 1962 & $\mathrm{~F}$ & 18 & 1,07 & $37.467(16,1)$ \\
Herdade Tiroleza & 1951 & $\mathrm{~F}$ & 6 & 1,06 & $44.938(19,3)$ \\
Santana Nababo & 1976 & $\mathrm{M}$ & 503 & 1,01 & $93.784(40,2)$ \\
\hline * Ano & & & & 5 \\
\hline
\end{tabular}

*Ano de nascimento não identificado indica desconhecido.

$\mathrm{Na}$ Tab. 2 são apresentadas as médias, os desvios-padrão e os valores máximos do coeficiente de parentesco entre cada um dos 16 principais ancestrais e a atual população de animais registrados da raça Mangalarga Marchador. Apesar de Tabatinga Cossaco (2,7\%) e Angaí Miron (2,2\%) ocuparem, respectivamente, a sexta e a sétima posições na classificação da contribuição para o pool gênico da população atual (Tab. 1), o parentesco médio de Abaíba Gim, o oitavo colocado, foi mais elevado do que o daqueles dois. Isto pode ser indicativo de acasalamentos desse garanhão com fêmeas mais aparentadas a ele (Tab. 2). 
Tabela 2. Médias, desvios-padrão e valores máximos do coeficiente de parentesco dos 16 ancestrais de maior contribuição genética para a atual população Mangalarga Marchador

\begin{tabular}{lcc}
\hline \multirow{2}{*}{ Ancestral } & \multicolumn{2}{c}{ Coeficiente de parentesco } \\
\cline { 2 - 3 } & Média \pm desvio-padrão & Máximo \\
\hline Providência Itu & $3,76 \pm 6,55$ & 81,25 \\
Herdade Alteza & $4,68 \pm 7,31$ & 75,00 \\
Tabatinga Predileto & $2,56 \pm 5,38$ & 75,00 \\
Abaíba Marengo & $2,54 \pm 5,50$ & 75,00 \\
Seta Caxias & $2,95 \pm 4,83$ & 50,00 \\
Tabatinga Cossaco & $1,77 \pm 5,36$ & 50,00 \\
Angaí Miron & $1,33 \pm 4,35$ & 75,00 \\
Abaíba Gim & $2,78 \pm 6,00$ & 80,07 \\
Abaíba Três Pontas & $0,80 \pm 2,90$ & 50,00 \\
Providência Prenda & $0,80 \pm 2,85$ & 50,00 \\
Malibu Santa Terezinha & $2,01 \pm 4,85$ & 63,04 \\
Tabatinga Fanfarra & $0,70 \pm 2,91$ & 50,00 \\
Herdade Ouro Preto & $0,98 \pm 3,05$ & 50,00 \\
Abaíba Jurema & $1,07 \pm 3,28$ & 50,00 \\
Herdade Tiroleza & $1,18 \pm 3,12$ & 50,00 \\
Santana Nababo & $1,89 \pm 4,97$ & 75,78 \\
\hline
\end{tabular}

Os criadores de Mangalarga Marchador utilizaram acasalamento em linha, provavelmente na tentativa de buscar maior padronização com animais considerados mais próximos do ideal. Nesse sentido, $50 \%$ dos ancestrais da raça apresentaram algum parentesco genético máximo acima de 50\%, indicativo de endogamia estreita. No caso do garanhão Providência Itu, o parentesco máximo observado, $81,3 \%$, foi, provavelmente, o resultado do seu acasalamento em linha com suas filhas e netas, sendo assim pai, avô e bisavô do produto final. Apesar desse garanhão ter a maior contribuição de genes para a população atual (Tab. 1), a égua Herdade Alteza foi a de maior média de parentesco genético (Tab. 2). É provável que a caracterização morfológica dessa égua tenha sido a desejada pelos criadores. Isto resultou não apenas no seu intenso uso (13 filhos), mas também no acasalamento entre parentes envolvendo ela mesma, seu filho Herdade Cadillac e, principalmente, seu filhoneto, Herdade Capricho (Costa, 2002).

Análises mais detalhadas da genealogia dos animais incluídos na Tab. 2 indicaram haver três grupos familiares não independentes. Os animais Providência Itu, Tabatinga Predileto e Abaiba Gim pertenciam a um mesmo grupo, sendo Abaíba Gim bisneto dos outros dois. Formaram outro grupo familiar os garanhões Malibu de Santa Terezinha, Angaí Miron e Tabatinga Predileto; o primeiro é neto do segundo e bisneto do terceiro garanhão. O terceiro grupo familiar foi formado por Santana Nababo, neto de Providência Itu. Desse modo, pode-se argumentar que a contribuição genética dos animais envolvidos nesses grupos familiares teria sido menor do que a apresentada na Tab. 1, pois parte dela era comum a vários ancestrais.

Em geral, os valores médios observados na Tab. 2 foram inferiores aos encontrados para as raças Tennessee Walking Horse, 15,5 e 17,4\%, para os dois principais garanhões, e Quarto de Milha, $6,0,6,7$ e 40,3\%, para os quatro principais garanhões (Fletcher, 1945; Rhoad e Kleberg, 1946). É importante considerar que as raças americanas são mais antigas do que a raça Mangalarga Marchador. Os coeficientes médios de parentesco observados foram mais elevados do que os $2,1 \%$ para o animal de maior influência na raça Árabe americana (Gazder, 1945).

As análises de componentes principais, incluindo os 16 animais de maior contribuição genética para a atual população, resultaram em 16 novas variáveis ou componentes principais (Tab. 3). Os seis primeiros componentes foram responsáveis por, aproximadamente, $78 \%$ da variação total.

Tabela 3. Autovalores, proporção da variância e variância acumulada dos componentes principais do parentesco entre os 16 principais ancestrais e a atual população da raça Mangalarga Marchador

\begin{tabular}{|c|c|c|c|}
\hline \multirow{2}{*}{$\begin{array}{l}\text { Componente } \\
\text { principal }\end{array}$} & \multirow{2}{*}{ Autovalor } & \multicolumn{2}{|c|}{ Proporção da variabilidade (\%) } \\
\hline & & Individual & Acumulado \\
\hline $1^{\circ}$ & 0,008864 & 24,1 & 24,1 \\
\hline $2^{\circ}$ & 0,006476 & 17,6 & 41,8 \\
\hline $3^{\circ}$ & 0,004663 & 12,7 & 54,5 \\
\hline $4^{\circ}$ & 0,003405 & 9,3 & 63,8 \\
\hline $5^{\circ}$ & 0,002929 & 8,0 & 71,7 \\
\hline $6^{\circ}$ & 0,002158 & 5,9 & 77,6 \\
\hline $7^{\circ}$ & 0,001537 & 4,2 & 81,8 \\
\hline $8^{\circ}$ & 0,001320 & 3,6 & 85,4 \\
\hline $9^{\circ}$ & 0,001082 & 2,9 & 88,3 \\
\hline $10^{\circ}$ & 0,000900 & 2,4 & 90,8 \\
\hline $11^{\circ}$ & 0,000804 & 2,2 & 93,0 \\
\hline $12^{\circ}$ & 0,000717 & 1,9 & 94,9 \\
\hline $13^{\circ}$ & 0,000658 & 1,8 & 96,7 \\
\hline $14^{\circ}$ & 0,000458 & 1,2 & 97,9 \\
\hline $15^{\circ}$ & 0,000452 & 1,2 & 99,2 \\
\hline $16^{\circ}$ & 0,000288 & 0,8 & 100,0 \\
\hline
\end{tabular}

Os resultados da contribuição de cada um dos 16 principais ancestrais da raça Mangalarga 
Marchador para os seis mais importantes componentes principais estão na Tab. 4. O animal Providência Itu teve maior importância no primeiro componente principal e a égua Herdade Alteza, a maior contribuição para o segundo componente. A contribuição dos animais Tabatinga Predileto e Tabatinga Cossaco foi mais evidente no terceiro componente principal. Malibu de Santa Terezinha e Abaíba Marengo tiveram maior contribuição no quarto componente, esse último também no quinto componente, e Santana Nababo no sexto componente principal.

Tabela 4. Componentes principais do parentesco entre os 16 principais ancestrais e a população atual da raça Mangalarga Marchador

\begin{tabular}{lcccccc}
\hline \multirow{2}{*}{ Ancestral } & \multicolumn{7}{c}{ Componente principal } \\
\cline { 2 - 7 } & $1^{\mathbf{o}}$ & $2^{\mathbf{0}}$ & $3^{\mathbf{0}}$ & $4^{\mathbf{0}}$ & $5^{\mathbf{o}}$ & $6^{\mathbf{0}}$ \\
\hline Providência Itu & 0,521923 & 0,403979 & $-0,26984$ & $-0,130059$ & $-0,101559$ & 0,113581 \\
Herdade Alteza & $-0,455083$ & 0,705451 & 0,150446 & $-0,031345$ & 0,030334 & 0,077377 \\
Tabatinga Predileto & 0,250968 & 0,031726 & 0,585726 & $-0,032958$ & 0,021792 & $-0,268241$ \\
Abaíba Marengo & 0,182996 & 0,106674 & $-0,122231$ & 0,453857 & 0,772702 & 0,198599 \\
Seta Caxias & $-0,300706$ & 0,377501 & 0,058114 & $-0,051379$ & 0,096293 & $-0,075478$ \\
Tabatinga Cossaco & 0,105620 & $-0,090403$ & 0,532583 & $-0,392282$ & 0,214512 & 0,476177 \\
Angaí Miron & 0,058967 & $-0,021208$ & 0,181735 & 0,508823 & $-0,260771$ & 0,162092 \\
Abaíba Gim & 0,471283 & 0,318051 & 0,131357 & $-0,064639$ & 0,029497 & $-0,495719$ \\
Abaíba Três Pontas & 0,102651 & 0,073812 & $-0,053297$ & $-0,004038$ & 0,020718 & 0,041901 \\
Providência Prenda & 0,083290 & 0,043833 & $-0,068017$ & 0,087292 & 0,213891 & 0,023580 \\
Malibu da S. Terezinha & 0,080902 & 0,113501 & 0,323715 & 0,545763 & $-0,320430$ & 0,168193 \\
Tabatinga Fanfarra & 0,047488 & $-0,036539$ & 0,225005 & $-0,150867$ & 0,086664 & 0,186662 \\
Herdade Ouro Preto & $-0,033280$ & 0,111705 & 0,041212 & 0,030731 & $-0,091342$ & 0,099843 \\
Abaíba Jurema & 0,089042 & 0,063481 & $-0,043754$ & $-0,035370$ & $-0,113298$ & 0,020259 \\
Herdade Tiroleza & $-0,086693$ & 0,062158 & $-0,009278$ & $-0,022611$ & 0,039281 & $-0,083231$ \\
Santana Nababo & 0,232450 & 0,180305 & $-0,206521$ & $-0,156410$ & $-0,271842$ & 0,531521 \\
\hline
\end{tabular}

Ficou evidenciada a existência de alguns grupos familiares englobando mais de um dos 16 principais ancestrais da raça. Assim, considerando os animais comuns a vários grupos, e na tentativa de reduzir o número de componentes principais, foram realizadas análises que incluíram apenas os oito primeiro animais, de acordo com a contribuição genética para a raça (Tab. 5). Os resultados (Tab. 6) correspondem a oito componentes principais, com os três primeiros explicando mais de $69 \%$ da variação total da contribuição genética para a população atual da raça. Se forem considerados os quatro primeiros componentes, essa explicação chega a, aproximadamente, $80 \%$ da variação existente na raça. A partir do quinto componente principal, o percentual de contribuição passou a ser menos relevante, razão da sua não inclusão nas análises e nas considerações subseqüentes.
Tabela 5. Autovalores, proporção da variância e variância acumulada dos componentes principais do parentesco entre os oito principais ancestrais da raça Mangalarga Marchador

\begin{tabular}{lccc}
\hline \multirow{2}{*}{$\begin{array}{l}\text { Componente } \\
\text { principal }\end{array}$} & \multirow{2}{*}{ Autovalor } & \multicolumn{2}{c}{ Proporção da variabilidade (\%) } \\
\cline { 3 - 4 } & & Individual & Acumulado \\
\hline $1^{\circ}$ & 0,008196 & 31,10 & 31,10 \\
$2^{\circ}$ & 0,006063 & 23,01 & 54,11 \\
$3^{\circ}$ & 0,004019 & 15,25 & 69,37 \\
$4^{\circ}$ & 0,002746 & 10,42 & 79,79 \\
$5^{\circ}$ & 0,002104 & 7,98 & 87,77 \\
$6^{\circ}$ & 0,001599 & 6,07 & 93,84 \\
$7^{\circ}$ & 0,000897 & 3,40 & 97,24 \\
$8^{\circ}$ & 0,000726 & 2,76 & 100,0 \\
\hline
\end{tabular}

$\mathrm{Na}$ Tab. 6 são apresentadas os oito principais ancestrais e os valores de cada um dos quatro componentes principais. Os animais mais associados ao primeiro componente principal foram Herdade Alteza, Providência Itu e Abaíba Gim. Os sinais negativos observados para Herdade Alteza e Seta Caxias significam que suas contribuições foram antagônicas à de 
Providência Itu e Abaíba Gim, com sinais positivos. Esses animais poderiam ser agrupados em dois conjuntos, um relativo a Herdade Alteza e outro a Providência Itu, pois, de acordo o pedigree de Abaíba Gim, ele é bisneto de Providência Itu, portanto, seu parentesco genético é 12,5\%. Mais ainda, apesar de Seta
Caxias ter menos importância do que Herdade Alteza para o primeiro componente principal, existe coerência nesse resultado. O garanhão Seta Caxias é avô e a égua Herdade Alteza é mãe e avó do garanhão que mais progênies deixou na raça Mangalarga Marchador, Herdade Capricho, filho de Herdade Cadillac.

Tabela 6. Componentes principais do parentesco genético entre os oito principais ancestrais e a população atual da raça Mangalarga Marchador

\begin{tabular}{lcccc}
\hline \multirow{2}{*}{ Ancestral } & \multicolumn{3}{c}{ Componente principal } \\
\cline { 2 - 5 } & $1^{\mathrm{o}}$ & $2^{\mathrm{o}}$ & $3^{\mathrm{o}}$ & $4^{\mathrm{o}}$ \\
\hline Providência Itu & 0,467970 & 0,487009 & $-0,312470$ & $-0,265692$ \\
Herdade Alteza & $-0,564614$ & 0,638174 & 0,130809 & 0,042335 \\
Tabatinga Predileto & 0,269970 & 0,114758 & 0,612853 & 0,116409 \\
Abaíba Marengo & 0,178673 & 0,152605 & $-0,264885$ & 0,916556 \\
Seta Caxias & $-0,357121$ & 0,344780 & 0,068743 & 0,048151 \\
Tabatinga Cossaco & 0,126259 & $-0,036612$ & 0,651846 & 0,127638 \\
Angaí Miron & 0,057793 & $-0,035681$ & 0,040187 & 0,199693 \\
Abaíba Gim & 0,459384 & 0,444535 & 0,090855 & $-0,125941$ \\
\hline
\end{tabular}

No segundo componente principal, a maior contribuição foi da égua Herdade Alteza, com coeficiente de 0,64. No terceiro componente principal, a maior contribuição foi dos animais Tabatinga Cossaco $(0,65)$ e Tabatinga Predileto $(0,61)$. Não houve indicação de que esses animais fossem parentes, mas foram utilizados como reprodutores em um mesmo criatório e, provavelmente, tiveram netos ou bisnetos em comum. O quarto componente principal teve em Abaíba Marengo o maior representante $(0,92)$, e em Angaí Miron o de menor importância na formação das famílias da raça Mangalarga Marchador. Angaí Miron é pai de Irapuru Bela Cruz, garanhão de grande importância na raça Mangalarga Marchador, e avô de Malibu de Santa Terezinha, o garanhão que apresentou maior número de animais com relação de parentesco diferente de zero (66,3\%; Tab. 1).

A Fig. 1 mostra as distâncias genéticas entre animais e sua contribuição para os dois primeiros componentes principais. Pelo posicionamento gráfico a em quadrantes opostos, observa-se que os animais relacionados com Herdade Alteza e Seta Caxias não foram usados como progenitores nos mesmos criatórios onde Angaí Miron e Tabatinga Cossaco deixaram descendentes.

Pela proximidade genética com Providência Itu, optou-se pela exclusão do garanhão Abaíba Gim das análises subseqüentes. Isto resultou em alteração desprezível na variância acumulada dos três primeiros componentes principais (Tab. $7 \mathrm{e}$ 8). No entanto, houve inversão no primeiro e no segundo componentes principais, evidenciando a importância do garanhão Providência Itu e da égua Herdade Alteza. Nessa segunda análise, o primeiro componente principal destacou Herdade Alteza com maior evidência do que na primeira. O garanhão Providência Itu ficou também em destaque no segundo componente principal. Esse resultado evidenciou, mais uma vez, a similaridade genética e a contribuição para o pool gênico da raça Mangalarga Marchador dos animais Abaíba Gim e Providência Itu, pois a exclusão do primeiro fez sobressair a contribuição do segundo e o distanciou da contribuição de Herdade Alteza e de Tabatinga Predileto. 


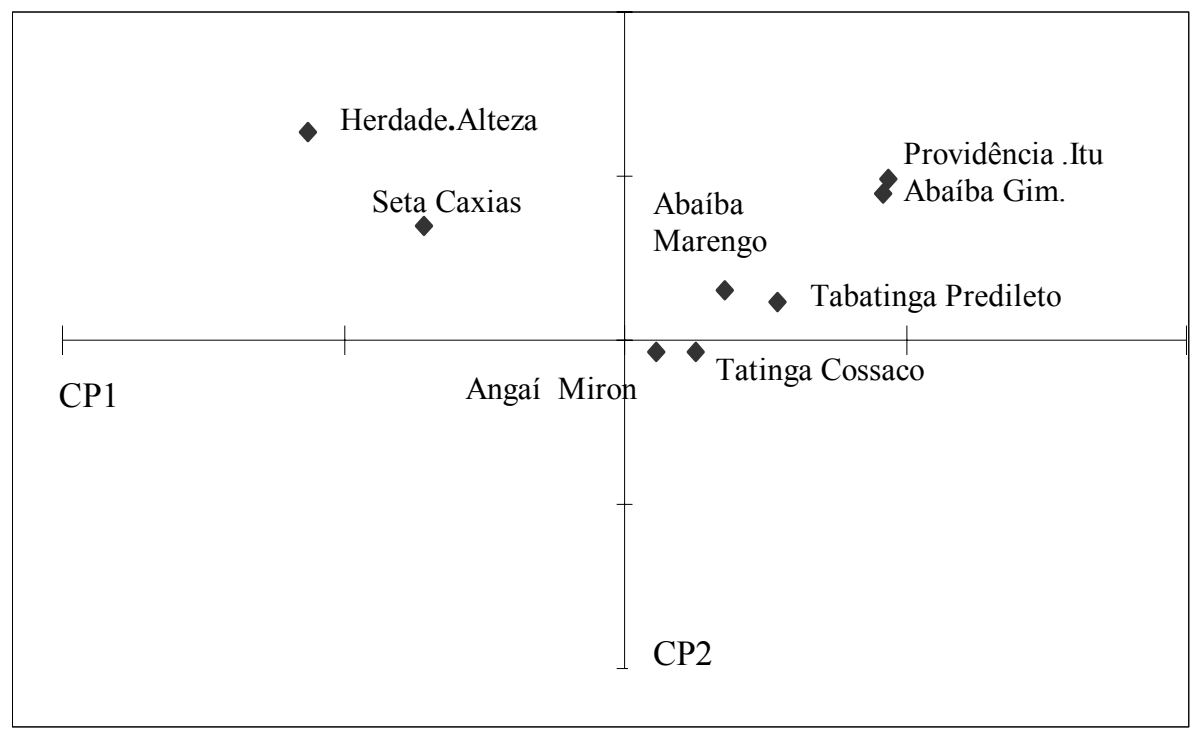

Figura 1. Representação esquemática do primeiro (CP1) e do segundo (CP2) componentes principais da análise entre o parentesco genético dos oito principais ancestrais da raça Mangalarga Marchador.

Tabela 7. Autovalores, proporção da variância e variância acumulada dos componentes principais do parentesco entre os principais ancestrais da raça Mangalarga Marchador, excluindo o garanhão Abaíba Gim

\begin{tabular}{lccc}
\hline $\begin{array}{l}\text { Componente } \\
\text { Principal }\end{array}$ & Autovalor & $\begin{array}{c}\text { Proporção da variabilidade (\%) } \\
\text { Individual }\end{array}$ & Acumulada \\
\hline $1^{\circ}$ & 0,007351 & 32,32 & 32,32 \\
$2^{\circ}$ & 0,004553 & 20,02 & 52,34 \\
$3^{\circ}$ & 0,00391 & 17,20 & 69,53 \\
$4^{\circ}$ & 0,002689 & 11,82 & 81,35 \\
$5^{\circ}$ & 0,002038 & 8,96 & 90,31 \\
$6^{\circ}$ & 0,001466 & 6,44 & 96,75 \\
$7^{\circ}$ & 0,000738 & 3,24 & 100,00 \\
\hline
\end{tabular}

O terceiro componente principal mostrou proximidade genética entre Tabatinga Predileto e Tabatinga Cossaco e, ainda, o quarto componente principal destacou a importância de Abaíba Marengo. A contribuição do garanhão Angaí Miron manteve-se praticamente inalterada em relação à análise anterior, demonstrando que não houve associação entre ele e Abaíba Gim.

Os resultados sugerem a existência de cinco grupos formadores da atual população da raça Mangalarga Marchador (Fig. 1 e 2). O primeiro grupo é formado pelos animais relacionados com Herdade Alteza e Seta Caxias; o segundo é formado pelos descendentes de Providência Itu, Abaíba Gim e Tabatinga Predileto; o terceiro é formado pelos descendentes de Abaíba Marengo; e o quarto e quinto grupos formados pelos descendentes de Tabatinga Cossaco e de Angaí Miron, respectivamente. Pode-se afirmar que esses cinco grupos constituem as famílias com maior importância para a atual população da raça e, ainda, que os animais Abaíba Marengo, Tabatinga Predileto, Tabatinga Cossaco e Angaí Miron devem ter, nessa ordem, relação decrescente com Providência Itu e Abaíba Gim. Como na análise anterior, os animais Tabatinga Cossaco e Angaí Miron mantiveram-se em quadrantes opostos ao de Herdade Alteza e Seta Caxias, constituindo assim, grupos distintos na formação da raça. Portanto, os resultados das análises de componentes principais sugerem que a atual raça Mangalarga Marchador está subdividida em linhagens e que elas podem ser agrupadas entre os descendentes de animais pertencentes aos grupos Herdade, Providência, Abaíba, Tabatinga e Angaí, nesta ordem de importância. 
Tabela 8. Componentes principais do parentesco entre os sete principais ancestrais e a população atual da raça Mangalarga Marchador

\begin{tabular}{lcccc}
\hline \multirow{2}{*}{ Ancestral } & \multicolumn{3}{c}{ Componente principal } \\
\cline { 2 - 4 } & $1^{\mathbf{0}}$ & $2^{\mathbf{o}}$ & $3^{\mathrm{o}}$ & $4^{\mathrm{o}}$ \\
\hline Providência Itu & $-0,241275$ & 0,856546 & $-0,027258$ & $-0,434702$ \\
Herdade Alteza & 0,798621 & 0,251430 & 0,217135 & 0,008826 \\
Tabatinga Predileto & $-0,187603$ & 0,037702 & 0,683163 & 0,070894 \\
Abaíba Marengo & $-0,120117$ & 0,421152 & $-0,070682$ & 0,867843 \\
Seta Caxias & 0,481960 & 0,095401 & 0,095401 & 0,047242 \\
Tabatinga Cossaco & $-0,131143$ & $-0,121191$ & 0,684864 & 0,011178 \\
Angaí Miron & $-0,069884$ & $-0,005869$ & 0,047556 & 0,224547 \\
\hline
\end{tabular}

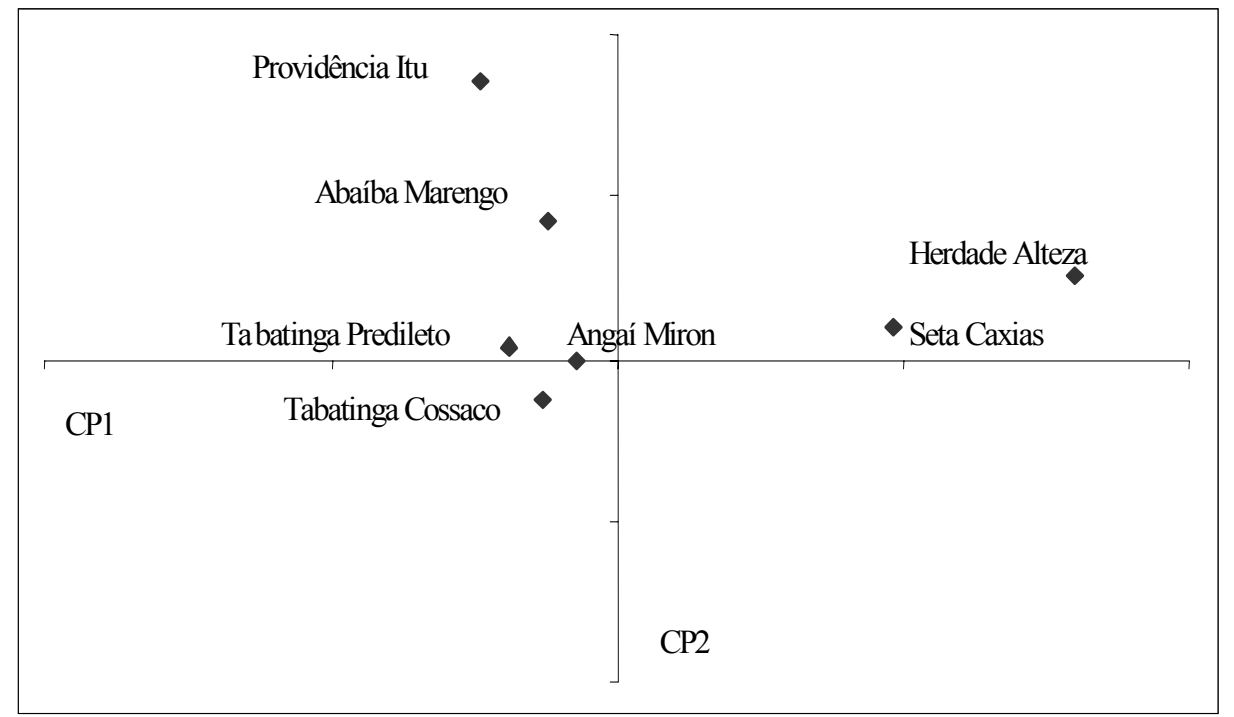

Figura 2. Representação esquemática do primeiro (CP1) e do segundo (CP2) componentes principais da análise entre o parentesco genético dos oito principais ancestrais da raça Mangalarga Marchador, excluindo Abaíba Gim.

\section{CONCLUSÕES}

Os criadores dos animais registrados da raça Mangalarga Marchador fizeram uso de acasalamentos entre parentes, provavelmente para a fixação de tipos fenotípicos desejados. O principal animal formador da raça Mangalarga Marchador foi a égua Herdade Alteza. Os resultados sugerem a existência de cinco grupos genéticos na atual população Mangalarga Marchador, associados aos descendentes de Herdade Alteza e Seta Caxias, de Providência Itu e de Tabatinga Predileto, de Abaíba Marengo, de Tabatinga Cossaco e de Angaí Miron, nessa ordem de importância.

\section{REFERÊNCIAS BIBLIOGRÁFICAS}

BARBOSA, C.G. Estudo morfométrico na raça Mangalarga Marchador: Uma abordagem multivariada, 1990. 77f. Disssertação (Mestrado) - Escola de Veterinária, Universidade Federal de Minas Gerais, Belo Horizonte.

BORTONI, R.F. Mangalarga Marchador e os outros cavalos de sela no Brasil. Uberaba: Grupo Rotal Ltda., 1991. 188p.

CASIUCH, R.L. O Romance da raça: Histórias do cavalo Mangalarga Marchador. São Paulo: Empresa das Artes, 1997. 252p. 
COSTA, M.D.; BERGMANN, J.A.G.; RESENDE, A.S.C. et al. Análise temporal da endogamia e do tamanho efetivo da população de eqüinos da raça Mangalarga Marchador. Arq. Bras. Med. Vet. Zootec., v.57, p.112-119, 2005.

DESTEFANIS, G.; BARGE, M.T.; BRUGIAPAGLIA, A. et al. The use of principal component analysis (PCA) o characterize beef. Meat Sci., v.56, p.255-259, 2000.

FLETCHER, J.L A study of the first fifty years of Tennessee Walking horse breeding. J. Hered., v.37, p.369-373, 1946.

FLETCHER, J.L. A genetic analysis of the American Quarter Horse. J. Hered., v.36, p.346-
352,1945

FUENTES GARCIA, F.; GARCIA, M.H.; MACARRO, A. et al. Morfoestructura del caballo Árabe en España. Arch. Zootec., v.36, p.269-282, 1987.

GAZDER, P.J. The genetic history of the Arabian Horse. J. Hered., v.45, p.95-98, 1954.

LUSH, J.L. Melhoramento genético dos animais domésticos. Rio de Janeiro: Centro de Publicações Técnicas da Aliança, 1964. 570p.

RHOAD, A.O.; KLEBERG, J.R. The developments of a superior family in the modern Quarter Horse. J. Hered., v.37, p.227-238, 1946. 